\title{
Reviewing the Evidence That Polypectomy Prevents Cancer
}

\author{
Charles J. Kahi, MD
}

\author{
Charles J. Kahi, MD, MS, FACP, FACG, AGAF, FASGE \\ Professor of Clinical Medicine \\ Indiana University School of Medicine \\ Gastroenterology Section Chief, Roudebush VA Medical Center \\ 1481 W 10th street, $111 \mathrm{G}$ \\ Indianapolis, IN 46202 \\ Phone: (317) 988-3682 \\ Fax: (317) 988-5313 \\ E-mail: ckahi2@iu.edu
}

\section{INTRODUCTION}

The concept of CRC screening has transformed over the past few decades, with the realization that the benefit is less from the detection of early curable-stage cancer, than it is from prevention of cancer via detection and elimination of premalignant lesions. The amenability to primary prevention is a fundamental characteristic of CRC which distinguishes it from other "screenable" cancers, where the focus is generally on secondary prevention via detection of early stage malignancy ${ }^{1}$. This paradigm originated in 1965 with Gilbertsen ${ }^{2}$, who postulated that CRC could be prevented by polypectomy, and was later supported by the biologic framework of the Fearon-Vogelstein adenoma-carcinoma sequence ${ }^{3}$. It is now accepted that most CRCs develop within precursor adenomatous or serrated polyps, and that interruption of the polyp-tocancer sequence prevents the development of CRC. The effect of this interruption on patient outcomes has been the subject of multiple investigations. Several observational studies have reported reduced CRC incidence and mortality after colonoscopy ${ }^{4-14}$. However, patients in 
these studies were heterogeneous, including those with no findings and those with various precursor polyp types and numbers. This affects the interpretability of the findings, because it is known from several "negative colonoscopy" studies ${ }^{15-19}$ that patients without polyps are a lowerrisk group among the larger average-risk population. It is important to make a distinction between these groups, because prevention of CRC by endoscopic procedures is not due to the identification of persons without polyps, but rather to the detection and complete resection of polyps in patients with colorectal neoplasia. In other words, the main effector of CRC prevention is polypectomy.

There are presently no data from randomized controlled trials (RCT) to determine the effect of polypectomy on CRC incidence and mortality. Isolating the effect of polypectomy would require a randomized design with a control group where polyps are left in situ without resection, which is not a reasonable nor ethical consideration. There are 4 large ongoing RCTs ${ }^{20-23}$ in Europe and the U.S. comparing colonoscopy to fecal immunochemical testing for CRC screening that could clarify the impact of polypectomy, but their results will not be available for years. Despite the lack of RCT-level data, the effectiveness of polypectomy to prevent CRC is indisputable. Proof of this assertion is derived from several lines of evidence, including epidemiologic data, RCTs of fecal occult blood tests (FOBT) and flexible sigmoidoscopy, and from observational colonoscopy studies.

\section{Epidemiologic observations}

Colorectal Cancer (CRC) is a worldwide scourge with globally increasing burden. However, from the epidemiologic standpoint, the United States has been an exception, with steadily decreasing incidence rates since the $1980 \mathrm{~s}^{24}$, and long-term projections predicting declines through $2030^{25}$. There has been debate regarding the relative contribution of risk factor modification to the US CRC epidemiological trends, because the declines began prior to the mass screening era ${ }^{26}$. However, it is impossible not to attribute a majority of the benefit to 
widespread awareness and compliance with screening, and resultant removal of precancerous polyps: In the US, CRC declines have been most noticeable in those 65 years and older, and have accelerated for proximal colon cancer in the past decade ${ }^{24}$, an observation likely driven by increased use of colonoscopy and polypectomy. The more recently noted increases in CRC incidence in persons $<50$ years old ${ }^{27}$, who are not routinely screened for $\mathrm{CRC}$, provides an indirect argument that polypectomy is largely responsible for CRC decreases in screeningeligible age groups. That more colonoscopy and polypectomy could alter CRC epidemiology at the population level is supported by recent evidence from Germany, where CRC incidence and mortality have begun to decrease 10 years after colonoscopy was added to the German national cancer screening program ${ }^{28}$.

\section{Evidence from FOBT studies}

Randomized controlled trials have consistently shown that screening with FOBT is associated with reductions in CRC mortality ranging from $15 \%$ to $33 \%^{29-33}$. The FOBT is primarily a test for the detection of $\mathrm{CRC}$, and it can be argued that the beneficial effect of FOBTbased screening strategies is derived from detection of early-stage cancers. However, studies reporting the long-term outcomes of patients after FOBT screening suggest that colonoscopy with polypectomy is in fact a major contributor to the observed reductions in CRC mortality. The Minnesota Colon Cancer Control Study ${ }^{34}$ randomized 46,551 participants to annual or biennial FOBT screening or usual care. Through 30 years of follow-up, screening was associated with lower CRC mortality with annual (RR 0.68; 0.56-0.82) and biennial screening (RR 0.78, $0.65-$ 0.93) compared to usual care, while all-cause mortality was not significantly different. Importantly, the CRC mortality reduction of $32 \%$ at 30 years was sustained throughout the observation period, and similar to estimates at earlier time points. If early detection of CRC was the primary mechanism by which FOBT screening leads to decreased CRC mortality, the 
benefit would be most apparent during the first few years of follow-up after removal of CRC cases from the cohort, then deteriorate over time. The lack of such an observation strongly suggests that in patients with positive FOBT, colonoscopy with polypectomy and subsequent colonoscopic surveillance are responsible for the sustained long-term reduction in CRC mortality. An earlier analysis of the Minnesota FOBT cohort attributed a $20 \%$ reduction in CRC incidence after 18 years to colonoscopy with resection of polyps ${ }^{35}$.

A more modest reduction in CRC mortality of $13 \%$ was reported after 20 years of followup of patients in the Nottingham FOBT RCT, and no reduction in CRC incidence despite the removal of over 600 large adenomas in the intervention $\mathrm{arm}^{36}$. It is important to note, though, that the Nottingham and Minnesota trials differed in key aspects, notably the use of nonrehydrated FOBT leading to lower positivity and subsequent colonoscopy rates, and lower participant compliance rates in the Nottingham RCT.

\section{Evidence from sigmoidoscopy studies}

The results of sigmoidoscopy-based screening have been extrapolated to colonoscopy because they are both structural examinations of the colon and utilize the same endoscopic technology. Four large sigmoidoscopy RCTs have reported significant reductions in CRC incidence and mortality (Table 1) and meta-analyses have reported overall CRC mortality reductions of about $28 \%^{37,38}$.

The UK RCT ${ }^{39}$ assessed over 170,000 participants who were assigned to sigmoidoscopy or control groups, and of which about $5 \%$ were referred to colonoscopy for large, histologically advanced, or multiple adenomas. In intention-to-treat analyses, after 11 years of follow-up, CRC incidence was reduced by $23 \%$ (hazard ratio $0.77,95 \% \mathrm{Cl} 0.70-0.84$ ) and mortality by $31 \%(0.69,0.59-0.82)$ in the sigmoidoscopy group. After median follow-up of 17 years, CRC incidence and mortality reductions were $26 \%$ and $30 \%$, respectively ${ }^{40}$. The 
Prostate, Lung, Colorectal, and Ovarian (PLCO) Cancer $\mathrm{RCT}^{41}$ randomized 154,900 participants to screening sigmoidoscopy (repeated at 3 or 5 years) or to usual care. After a median of 12 years, CRC incidence was reduced by $21 \%$, and CRC mortality by $26 \%$. It is, however, difficult to isolate the effect of polypectomy performed in the sigmoidoscopy RCTs and separate it from that of subsequent colonoscopies, because these employed different polyp resection policies at the time of sigmoidoscopy, different colonoscopy referral strategies, and colonoscopy utilization and contamination varied between studies. For example, in the PLCO trial, patients with polyps at sigmoidoscopy were advised to undergo colonoscopy with about $80 \%$ compliance rate; conversely, the contamination rates in the usual care arm were $26 \%$ for flexible sigmoidoscopy and $34 \%$ for colonoscopy ${ }^{41}$. A meta-analysis showed that colonoscopy was associated with a $40 \%$ to $60 \%$ lower risk of incident CRC and death from CRC than sigmoidoscopy, which was statistically significant only for deaths due to proximal cancer ${ }^{42}$.

\section{Evidence from colonoscopy studies}

The first colonoscopy study to demonstrate unequivocally that polypectomy prevents CRC was the National Polyp Study (NPS) ${ }^{43}$. The NPS cohort included 1418 patients who underwent colonoscopy with resection of at least one adenoma, and followed for a mean of 6 years. Five asymptomatic CRCs were detected during surveillance, corresponding to a $76 \%$ reduction in CRC compared with a Surveillance, Epidemiology, and End Results (SEER) reference group, and no CRC deaths occurred. The long-term NPS follow up study ${ }^{44}$ provides compelling proof of the effectiveness of polypectomy to prevent CRC: The cohort included 2602 patients with adenomas (including the 1418 who were randomized in the original NPS assessing surveillance intervals after colonoscopy) followed for up to 23 years after polypectomy. Compared to a SEER control population, CRC mortality was reduced by $53 \%$ (95\% Cl 20\%-74\%), and the reduction for the first 10 years was similar to after 10 years of 
follow-up. In addition, CRC mortality was similar among for adenoma patients compared to an internal control group with nonadenomatous polyps for the first 10 years after polypectomy (relative risk, $1.2 ; 95 \% \mathrm{Cl}, 0.1$ to 10.6$)$.

An Italian observational prospective cohort study ${ }^{45}$ of 1693 patients who underwent colonoscopic polypectomy of adenomas $\geq 5 \mathrm{~mm}$ reported a $66 \%(95 \% \mathrm{Cl} 37 \%-77 \%) \mathrm{CRC}$ incidence reduction, compared to the general Italian population. Adenoma cohort studies published after the NPS and Italian study showed far less impressive reductions in CRC incidence after polypectomy. The Funen Adenoma Follow-up Study ${ }^{46}$, which assessed surveillance intervals in patients with adenomas, reported significant reductions in CRC incidence and mortality for up to 24 years after adenoma resection: Compared to the Danish population, CRC incidence RR was 0.65 (95\% Cl 0.43-0.95) and CRC death RR was 0.12 (95\% Cl 0.03-0.36). The Wheat Bran Fiber Trial ${ }^{47}$ and Polyp Prevention Trial ${ }^{48}$ assessed the effect of fiber to prevent adenoma recurrence after polypectomy, and both reported much higher CRC incidence rates compared to the NPS (2.2 versus 0.6 per 1000 patient-years). Another study ${ }^{49}$ combined data from 3 adenoma chemoprevention RCTs which assessed the effect of calcium, folic acid, antioxidants, and aspirin on recurrence rates of colorectal adenomas after colonoscopy and polypectomy. The overall incidence of CRC was 1.74 (95\% Cl, 1.05-2.72) per 1000 person-years of follow-up, compared to 0.6 and 0.4 in the NPS and Italian studies, respectively, and was not significantly different from expected incidence based on SEER data (standardized incidence ratio for $\mathrm{CRC}, 0.98 ; 95 \% \mathrm{Cl}, 0.63-1.54$ ).

The potential reasons for these discrepant findings are many ${ }^{50}$. First, the NPS included a small number of experienced endoscopists, and there was significant focus on ensuring complete adenoma clearance prior to enrollment: patients with adenomas larger than $3 \mathrm{~cm}$ were excluded, and about $13 \%$ of the cohort underwent more than one baseline colonoscopy. Second, there were important methodological differences, including duration of follow up, 
distinction between prevalent and incident CRC cases, the characteristics and CRC risk of the groups chosen for comparison, and frequency of surveillance colonoscopies after the index procedure. Finally, the quality of colonoscopy, notably neoplasia detection and completeness of polypectomy, were likely a contributing factor. These studies were conducted in an era which preceded the recognition of the importance of colonoscopy quality and its impact on the risk of post-colonoscopy $\mathrm{CRC}^{51,52}$. While information about endoscopists' adenoma detection rates and completeness of polypectomy is not available, the characteristics of the incident cancers reported in these studies strongly suggest that colonoscopy quality is a major factor, as most would qualify as interval or post-colonoscopy CRC based on current definitions. For example, in the NPS, 3 of 5 incident cancers were detected 3 years after the index procedure, all 9 cancers in the Wheat Bran Fiber Trial were found within 3 years, whereas 10 of 13 CRC in the Polyp Prevention trial were judged to be due to missed cancer, incomplete polypectomy, or inadequate biopsy. In the combined chemoprevention trial, 17 of $19 \mathrm{CRC}$ were detected within 4 years of the baseline colonoscopy and most were in the proximal colon.

The central importance of polypectomy quality is not a theoretical one. In the landmark Complete Adenoma Resection (CARE) study ${ }^{53}$, investigators biopsied the margins of 346 polypectomy sites, and found an incomplete resection rate (IRR) of $10.1 \%(95 \% \mathrm{Cl} 6.9 \%$ $13.3 \%$ ), and ranged from $6.5 \%$ to $22.7 \%$ among endoscopists. Larger polyps were more likely to be incompletely resected than smaller polyps (17.3\% vs. $6.8 \%)$. The IRR of $10 \%$, alarming enough by itself, is likely an underestimate of the true prevalence of this problem in clinical practice, because study endoscopists were aware that they participating in research and that their performance was being scrutinized. It is currently estimated that between $10 \%$ and $25 \%$ of PCCRC are due to incomplete polypectomy.

More recent studies have further highlighted the effect of polypectomy on CRC prevention, and the importance of continued surveillance in select higher-risk patients. An 
administrative claims-based study from Ontario ${ }^{54}$ assessed whether characteristics of endoscopists are associated with risk of PCCRC in 14,064 patients. In multivariate analyses, patients with proximal cancers undergoing colonoscopy by endoscopists who performed polypectomies at high rates had a lower risk of PCCRC. Compared to $<10 \%$ polypectomy rate reference, the OR was 0.52 if the polypectomy rate was $25 \%$ to $29 \%$, and 0.61 for rates $>30 \%$. Conversely, distal CRC was not associated with polypectomy rate. A large prospective study ${ }^{14}$ examined the association of colonoscopy and sigmoidoscopy with CRC incidence and mortality among 88,902 participants in the Nurses' Health Study and the Health Professionals Follow-up Study. In follow-up of over 22 years, compared to patients who had not undergone lower endoscopy, the multivariate hazard ratios for CRC among participants were 0.57 (95\% Cl, 0.45 0.72) after resection of adenomatous polyps, $0.60(95 \% \mathrm{Cl}, 0.53-0.68)$ after negative sigmoidoscopy, and $0.44(95 \% \mathrm{Cl}, 0.38-0.52)$ after negative colonoscopy. Polypectomy was associated with reduced distal $\mathrm{CRC}$ incidence (HR 0.40;95\% $\mathrm{Cl}, 0.27-0.59$ ), although proximal colon cancer incidence was not significantly different. One possible advantage of this study over the NPS is that the polypectomy and control groups were derived from the same background population, allowing more direct comparison of $\mathrm{CRC}$ incidence rates after polypectomy and adjustment for confounding factors.

A French population-based cohort study ${ }^{55}$ investigated CRC incidence in 5779 patients with adenomas, followed for a median of 7.7 years. Compared with the general French population, $87 \mathrm{CRC}$ were diagnosed versus 69 expected, for a standardized incidence ratio (SIR) of $1.26(95 \% \mathrm{Cl} 1.01-1.56) . \mathrm{CRC}$ risk depended on the features of the index adenoma and whether surveillance colonoscopy occurred: The SIR was $2.23(95 \% \mathrm{Cl} 1.67-2.92)$ for advanced adenomas compared to $0.68(95 \% \mathrm{Cl}$ 0.44-0.99) for non-advanced adenomas. For advanced adenomas, the SIR decreased to $1.10(95 \% \mathrm{Cl} 0.62-1.82)$ for patients who underwent colonoscopic surveillance, but increased to 4.26 (95\% Cl 2.89-6.04) for those who did not. 
A population-based study from Norway ${ }^{56}$ followed a cohort of 40,826 patients who underwent resection of colorectal adenomas between 1993 and 2007, and followed for a median of 7.7 years. Compared to the general Norwegian population, $383 \mathrm{CRC}$ deaths were recorded (398 expected) for a standardized mortality ratio of $0.96(95 \% \mathrm{Cl}: 0.87-1.06)$. CRC mortality was increased in high-risk adenoma patients (SMR, 1.16; 95\% Cl, 1.02- 1.31), and decreased among those with low-risk adenomas (SMR, 0.75; 95\% Cl, 0.63-0.88).

A study ${ }^{57}$ based on a Northern Ireland polyp registry reported a nearly 3-fold increased $\mathrm{CRC}$ risk among 6,972 adenoma patients, and the excess risk was associated with inadequate colon clearance and follow up after polypectomy.

Additional insight can be gained from follow-up of the subgroup of nearly 16,000 participants who underwent colonoscopy following abnormal findings on sigmoidoscopy ${ }^{58}$. When stratified according to adenoma findings at colonoscopy, and after a median of 13 years of follow-up, CRC incidence rates (per 10000 person-years) were 20.0 (95\% Cl, 15.3-24.7) for advanced adenoma, 9.1 (95\% Cl, 6.7-11.5) for nonadvanced adenoma, and 7.5 (95\% Cl, 5.8$9.7 ; n=71$ ) for no adenoma. Participants with advanced adenoma were about 2.5 times more likely to develop or die from CRC compared with participants with no adenoma. There were no significant differences in CRC incidence and mortality between participants with nonadvanced adenoma compared with no adenoma. 


\section{REFERENCES}

1. Fletcher R, Fletcher, S, Wagner, E. Clinical Epidemiology The Essentials, 3rd edition. Philadelphia, Pennsylvania: Lippincott Williams and Wilkins, 1996.

2. Gilbertsen VA, Knatterud GL, Lober PH, et al. Invasive Carcinoma of the Large Intestine: A Preventable Disease? Surgery 1965;57:363-5.

3. Vogelstein B, Fearon ER, Hamilton SR, et al. Genetic alterations during colorectal-tumor development. N Engl J Med 1988;319:525-32.

4. Kahi CJ, Imperiale TF, Juliar BE, et al. Effect of screening colonoscopy on colorectal cancer incidence and mortality. Clin Gastroenterol Hepatol 2009;7:770-5; quiz 711.

5. Lieberman DA, Weiss DG, Bond JH, et al. Use of colonoscopy to screen asymptomatic adults for colorectal cancer. Veterans Affairs Cooperative Study Group 380. N Engl J Med 2000;343:162-8.

6. Lieberman DA, Weiss DG, Harford WV, et al. Five-year colon surveillance after screening colonoscopy. Gastroenterology 2007;133:1077-85.

7. Doubeni CA, Corley DA, Quinn VP, et al. Effectiveness of screening colonoscopy in reducing the risk of death from right and left colon cancer: a large community-based study. Gut 2016.

8. Doubeni CA, Weinmann S, Adams K, et al. Screening colonoscopy and risk for incident late-stage colorectal cancer diagnosis in average-risk adults: a nested case-control study. Ann Intern Med 2013;158:312-20.

9. Brenner $\mathrm{H}, \mathrm{Chang}$-Claude J, Jansen $\mathrm{L}$, et al. Reduced risk of colorectal cancer up to 10 years after screening, surveillance, or diagnostic colonoscopy. Gastroenterology 2014;146:709-17.

10. Brenner $\mathrm{H}$, Chang-Claude J, Seiler $\mathrm{CM}$, et al. Protection from colorectal cancer after colonoscopy: a population-based, case-control study. Ann Intern Med 2011;154:22-30.

11. Brenner $\mathrm{H}$, Hoffmeister $\mathrm{M}$, Arndt $\mathrm{V}$, et al. Protection from right- and left-sided colorectal neoplasms after colonoscopy: population-based study. J Natl Cancer Inst;102:89-95.

12. Baxter NN, Goldwasser MA, Paszat LF, et al. Association of colonoscopy and death from colorectal cancer. Ann Intern Med 2009;150:1-8.

13. Baxter NN, Warren JL, Barrett MJ, et al. Association between colonoscopy and colorectal cancer mortality in a US cohort according to site of cancer and colonoscopist specialty. J Clin Oncol 2012;30:2664-9.

14. Nishihara R, Wu K, Lochhead $\mathrm{P}$, et al. Long-term colorectal-cancer incidence and mortality after lower endoscopy. N Engl J Med 2013;369:1095-105.

15. Lee JK, Jensen CD, Levin TR, et al. Long-term Risk of Colorectal Cancer and Related Deaths After a Colonoscopy With Normal Findings. JAMA Intern Med 2018.

16. Brenner $\mathrm{H}$, Chang-Claude J, Seiler $\mathrm{CM}$, et al. Long-term risk of colorectal cancer after negative colonoscopy. J Clin Oncol 2011;29:3761-7.

17. Lakoff J, Paszat LF, Saskin R, et al. Risk of developing proximal versus distal colorectal cancer after a negative colonoscopy: a population-based study. Clin Gastroenterol Hepatol 2008;6:1117-21; quiz 1064.

18. Singh $H$, Turner $D$, Xue $L$, et al. Risk of developing colorectal cancer following a negative colonoscopy examination: evidence for a 10 -year interval between colonoscopies. JAMA 2006;295:2366-73. 
19. Samadder NJ, Pappas L, Boucherr KM, et al. Long-Term Colorectal Cancer Incidence After Negative Colonoscopy in the State of Utah: The Effect of Family History. Am J Gastroenterol 2017;112:1439-1447.

20. Dominitz JA, Robertson DJ, Ahnen DJ, et al. Colonoscopy vs. Fecal Immunochemical Test in Reducing Mortality From Colorectal Cancer (CONFIRM): Rationale for Study Design. Am J Gastroenterol 2017;112:1736-1746.

21. Kaminski MF, Bretthauer M, Zauber AG, et al. The NordICC Study: rationale and design of a randomized trial on colonoscopy screening for colorectal cancer. Endoscopy 2012;44:695-702.

22. Quintero E, Castells A, Bujanda L, et al. Colonoscopy versus fecal immunochemical testing in colorectal-cancer screening. N Engl J Med 2012;366:697-706.

23. Colonoscopy and FIT as Colorectal Cancer Screening Test in the

Average Risk Population [clinical trial]. Accessed at www.clinicaltrials

.gov/ct2/show/NCT02078804 on 18 January 2019.

24. Siegel RL, Miller KD, Jemal A. Cancer statistics, 2016. CA Cancer J Clin 2016;66:7-30.

25. Tsoi KKF, Hirai HW, Chan FCH, et al. Predicted Increases in Incidence of Colorectal Cancer in Developed and Developing Regions, in Association With Ageing Populations. Clin Gastroenterol Hepatol 2017;15:892-900 e4.

26. Welch HG, Robertson DJ. Colorectal Cancer on the Decline--Why Screening Can't Explain It All. N Engl J Med 2016;374:1605-7.

27. Siegel RL, Fedewa SA, Anderson WF, et al. Colorectal Cancer Incidence Patterns in the United States, 1974-2013. J Natl Cancer Inst 2017;109.

28. Brenner H, Schrotz-King P, Holleczek B, et al. Declining Bowel Cancer Incidence and Mortality in Germany. Dtsch Arztebl Int 2016;113:101-6.

29. Hardcastle JD, Chamberlain JO, Robinson MH, et al. Randomised controlled trial of faecal-occultblood screening for colorectal cancer. Lancet 1996;348:1472-7.

30. Jorgensen OD, Kronborg O, Fenger $\mathrm{C}$. A randomised study of screening for colorectal cancer using faecal occult blood testing: results after 13 years and seven biennial screening rounds. Gut 2002;50:29-32.

31. Kronborg $\mathrm{O}$, Fenger $\mathrm{C}$, Olsen J, et al. Randomised study of screening for colorectal cancer with faecal-occult-blood test. Lancet 1996;348:1467-71.

32. Faivre J, Dancourt V, Lejeune $\mathrm{C}$, et al. Reduction in colorectal cancer mortality by fecal occult blood screening in a French controlled study. Gastroenterology 2004;126:1674-80.

33. Mandel JS, Bond JH, Church TR, et al. Reducing mortality from colorectal cancer by screening for fecal occult blood. Minnesota Colon Cancer Control Study. N Engl J Med 1993;328:1365-71.

34. Shaukat A, Mongin SJ, Geisser MS, et al. Long-term mortality after screening for colorectal cancer. N Engl J Med 2013;369:1106-14.

35. Mandel JS, Church TR, Bond JH, et al. The effect of fecal occult-blood screening on the incidence of colorectal cancer. N Engl J Med 2000;343:1603-7.

36. Scholefield JH, Moss SM, Mangham CM, et al. Nottingham trial of faecal occult blood testing for colorectal cancer: a 20-year follow-up. Gut 2012;61:1036-40.

37. Elmunzer BJ, Hayward RA, Schoenfeld PS, et al. Effect of flexible sigmoidoscopy-based screening on incidence and mortality of colorectal cancer: a systematic review and meta-analysis of randomized controlled trials. PLoS Med 2012;9:e1001352.

38. Holme $\mathrm{O}$, Bretthauer $\mathrm{M}$, Fretheim A, et al. Flexible sigmoidoscopy versus faecal occult blood testing for colorectal cancer screening in asymptomatic individuals. Cochrane Database Syst Rev 2013:CD009259. 
39. Atkin WS, Edwards R, Kralj-Hans I, et al. Once-only flexible sigmoidoscopy screening in prevention of colorectal cancer: a multicentre randomised controlled trial. Lancet 2010;375:1624-33.

40. Atkin W, Wooldrage $\mathrm{K}$, Parkin DM, et al. Long term effects of once-only flexible sigmoidoscopy screening after 17 years of follow-up: the UK Flexible Sigmoidoscopy Screening randomised controlled trial. Lancet 2017;389:1299-1311.

41. Schoen RE, Pinsky PF, Weissfeld JL, et al. Colorectal-cancer incidence and mortality with screening flexible sigmoidoscopy. N Engl J Med 2012;366:2345-57.

42. Brenner H, Stock C, Hoffmeister M. Effect of screening sigmoidoscopy and screening colonoscopy on colorectal cancer incidence and mortality: systematic review and meta-analysis of randomised controlled trials and observational studies. BMJ 2014;348:g2467.

43. Winawer SJ, Zauber AG, Ho MN, et al. Prevention of colorectal cancer by colonoscopic polypectomy. The National Polyp Study Workgroup. N Engl J Med 1993;329:1977-81.

44. Zauber AG, Winawer SJ, O'Brien MJ, et al. Colonoscopic polypectomy and long-term prevention of colorectal-cancer deaths. N Engl J Med 2012;366:687-96.

45. Citarda F, Tomaselli G, Capocaccia R, et al. Efficacy in standard clinical practice of colonoscopic polypectomy in reducing colorectal cancer incidence. Gut 2001;48:812-5.

46. Jorgensen $\mathrm{OD}$, Kronborg $\mathrm{O}$, Fenger $\mathrm{C}$, et al. Influence of long-term colonoscopic surveillance on incidence of colorectal cancer and death from the disease in patients with precursors (adenomas). Acta Oncol 2007;46:355-60.

47. Alberts DS, Martinez ME, Roe DJ, et al. Lack of effect of a high-fiber cereal supplement on the recurrence of colorectal adenomas. Phoenix Colon Cancer Prevention Physicians' Network. N Engl J Med 2000;342:1156-62.

48. Schatzkin A, Lanza E, Corle D, et al. Lack of effect of a low-fat, high-fiber diet on the recurrence of colorectal adenomas. Polyp Prevention Trial Study Group. N Engl J Med 2000;342:1149-55.

49. Robertson DJ, Greenberg ER, Beach M, et al. Colorectal cancer in patients under close colonoscopic surveillance. Gastroenterology 2005;129:34-41.

50. Hewett DG, Kahi CJ, Rex DK. Does colonoscopy work? J Natl Compr Canc Netw;8:67-76; quiz 77.

51. Corley DA, Jensen CD, Marks AR, et al. Adenoma detection rate and risk of colorectal cancer and death. N Engl J Med 2014;370:1298-306.

52. Kaminski MF, Regula J, Kraszewska E, et al. Quality indicators for colonoscopy and the risk of interval cancer. N Engl J Med;362:1795-803.

53. Pohl H, Srivastava A, Bensen SP, et al. Incomplete polyp resection during colonoscopy-results of the complete adenoma resection (CARE) study. Gastroenterology 2013;144:74-80 e1.

54. Baxter NN, Sutradhar R, Forbes SS, et al. Analysis of administrative data finds endoscopist quality measures associated with postcolonoscopy colorectal cancer. Gastroenterology 2011;140:65-72.

55. Cottet V, Jooste V, Fournel I, et al. Long-term risk of colorectal cancer after adenoma removal: a population-based cohort study. Gut 2012;61:1180-6.

56. Holme $\mathrm{O}$, Bretthauer $\mathrm{M}$, Eide $\mathrm{TJ}$, et al. Long-term risk of colorectal cancer in individuals with serrated polyps. Gut 2015;64:929-36.

57. Coleman HG, Loughrey MB, Murray LJ, et al. Colorectal Cancer Risk Following Adenoma Removal: A Large Prospective Population-Based Cohort Study. Cancer Epidemiol Biomarkers Prev 2015;24:1373-80.

58. Click B, Pinsky PF, Hickey T, et al. Association of Colonoscopy Adenoma Findings With Long-term Colorectal Cancer Incidence. JAMA 2018;319:2021-2031. 